\title{
Subacute Oral Toxicity of Yukmijiwhang-Tang in Crl:CD Sprague-Dawley Rats and Its Cytotoxicity
}

\author{
Soo-Jin Jeong, ${ }^{1}$ Chang-Seob Seo, ${ }^{1}$ Jung-Im Huh, ${ }^{2}$ and Hyeun-Kyoo Shin ${ }^{1}$ \\ ${ }^{1}$ Herbal Medicine Formulation Research Group, Herbal Medicine Research Division, Korea Institute of Oriental Medicine, \\ Daejeon 305-811, Republic of Korea \\ ${ }^{2}$ Division of Non-Clinical Studies, Korea Institute of Toxicology, Daejeon 305-343, Republic of Korea
}

Correspondence should be addressed to Hyeun-Kyoo Shin; hkshin@kiom.re.kr

Received 15 May 2014; Revised 22 August 2014; Accepted 25 August 2014; Published 5 November 2014

Academic Editor: Dae Gill Kang

Copyright (C) 2014 Soo-Jin Jeong et al. This is an open access article distributed under the Creative Commons Attribution License, which permits unrestricted use, distribution, and reproduction in any medium, provided the original work is properly cited.

\begin{abstract}
Background. The traditional herbal formula Yukmijiwhang-tang (YMJ) consists of six medicinal herbs and has been used to treat dysuria, diabetic mellitus, and neurosis in Korea, China, and Japan. Here we report safety information on its subacute toxicity and the cytotoxicity. Methods. YMJ extract was administered to SD rats at various dosages for 4 weeks. We monitored clinical signs, mortality, body and organ weights, food intake, and hematological and serum biochemistry factors. For cytotoxicity testing, each cell line was treated with various concentrations of YMJ for $24 \mathrm{~h}$. Results. YMJ treatment had no significant effects on changes in clinical signs, body weight, or food intake in male or female rats. In male rats, YMJ treatment decreased the absolute weights of the epididymides and serum Na levels. In female rats, YMJ significantly reduced the prothrombin time (PT) and serum creatine level. However, the changes were not severe and were considered to be in the normal physiological range for rats. The no-observedadverse-effect-level (NOAEL) was estimated to be $2000 \mathrm{mg} / \mathrm{kg} / \mathrm{day}$. YMJ extract did not exert any cytotoxicity against 23 tested cell lines. Conclusions. Our data provide scientific evidence on the safety of YMJ for potential development as a prescription drug.
\end{abstract}

\section{Introduction}

Herbal medicine is a part of complementary and alternative medicine (CAM) including acupuncture, moxibustion, and other therapeutic methods. Traditionally, herbal medicine was used to restore a balance of energy in the body to maintain health rather than treat diseases. Many recent preclinical and clinical studies have provided scientific evidence on the efficacies of herbal medicines as therapeutic agents for various diseases. However, for drug development of herbal medicines, the safety information is scarce compared with synthetic chemical drugs. According to regulations of the United States Food and Drug Administration (FDA), dietary supplements including herbal products are different from Western prescription medicines or over-the-counter (OTC) drugs. Although herbal medicines are generally thought to be safe, some of them have toxicity and can induce drug interaction with others. Therefore, toxicity evaluation for herbal medicine should be considered as an important step prior to efficacy studies.
Yukmijiwhang-tang (YMJ; Rokumi-jio-gan in Japan, Liu Wei Di Huang tang in China) is a traditional herbal cocktail composed of six medicinal herbs: Rehmanniae Radix Preparata, Corni Fructus, Dioscoreae Rhizoma, Moutan Cortex, Poria Sclerotium, and Alismatis Rhizoma [1]. Basically, YMJ is a modified formula derived from Palmijihwangtang (PMJ) by subtracting two herbs Plantago asiatica Linn. and Cinnamomum cassia Presl. YMJ was one of the most frequently prescribed herbal formulas found during the Song dynasty of China. YMJ has been used traditionally for the treatment of renal diseases, edema, diabetes, neurosis, and aging in Korea and China. Modern research has reported various biological activities of YMJ or YMJ derivatives (YMJD), such as antiosteoporotic [2, 3], antiamnesia [4, 5], antiasthmatic [6], and memory-enhancing [7] effects. In addition, our group recently reported the efficacy of YMJ treatment against benign prostatic hyperplasia in vivo [8].

Here we investigated the subacute toxicity of 4-week repeated oral doses of YMJ in a Crl:CD (SD) rat model 
according to guidelines established by the Organization for Economic Cooperation and Development (OECD) for the testing of chemicals in accordance with current Good Laboratory Practice regulations [9]. In addition, the cytotoxicity of YMJ was evaluated against various cell lines of different origins.

\section{Materials and Methods}

2.1. Chemicals and Reagents. 5-(Hydroxymethyl)furfural (5$\mathrm{HMF}$ ) and gallic acid were purchased from Sigma-Aldrich (St. Louis, MO, USA). Loganin, paeoniflorin, and paeonol were obtained from Wako Pure Chemicals (Osaka, Japan). Morroniside was purchased from NPC BioTechnology Inc. (Daejeon, Korea). The purity of each component was determined to be above $98 \%$ by high performance liquid chromatography (HPLC) analysis. HPLC-grade reagents, methanol, acetonitrile, and water were obtained from J. T. Baker (Phillipsburg, NJ, USA). Acetic acid was procured from Junsei (Tokyo, Japan).

2.2. Plant Materials. Each of the six herbal medicines comprising YMJ was purchased from Omniherb (Yeongcheon, Korea) and HMAX (Chungbuk, Korea). The sources of these herbal medicines were confirmed taxonomically by Professor Je Hyun Lee, Dongguk University, Gyeongju, Korea. A voucher specimen (2008-KE07-1 KE07-6) has been deposited at the Herbal Medicine Formulation Research Group, Korea Institute of Oriental Medicine.

2.3. Preparation of YMJ Water Extract. A YMJ decoction consisting of six herbs (Rehmannia glutinosa, Cornus officinalis, Dioscorea batatas, Paeonia suffruticosa, Poria cocos, and Alisma orientale) was mixed (Table 1; $20.6 \mathrm{~kg} ; 25.0 \mathrm{~g} \times 825$ ) and extracted in a 10 -fold mass of water at $100^{\circ} \mathrm{C}$ for $2 \mathrm{~h}$ under pressure $\left(1 \mathrm{kgf} / \mathrm{cm}^{2}\right)$ using an electric extractor (COSMOS660; Kyungseo Machine Co., Incheon, Korea), and the water extract was then filtered through a standard sieve (number 270, $53 \mu \mathrm{m}$; Chung Gye Sang Gong Sa, Seoul, Korea) and the solution was evaporated to dryness and freeze-dried to give a powder. The yield of YMJ water extract was $27.0 \%$ (5.6 kg).

2.4. Preparation of Standard and Sample Solutions. Standard stock solutions of 5-HMF, gallic acid, paeoniflorin, paeonol, loganin, and morroniside were dissolved in methanol at $1.0 \mathrm{mg} / \mathrm{mL}$ and stored below $4^{\circ} \mathrm{C}$. Working standard solutions were prepared by serial dilution of stock solutions with methanol. For HPLC analysis, $200 \mathrm{mg}$ of lyophilized YMJ was dissolved in $20 \mathrm{~mL}$ of distilled water and passed through a $0.2 \mu \mathrm{m}$ syringe filter (Woongki Science, Seoul, Korea) before injection into the HPLC system.

2.5. HPLC Analysis of YMJ Sample. The chromatographic analysis for simultaneous determination used a Shimadzu Prominence LC-20A system (Shimadzu Co., Kyoto, Japan), consisting of a solvent delivery unit, an online degasser, a column oven, an autosampler, and a photodiode array (PDA) detector. The data processor employed Shimadzu LCsolution
TABLE 1: Composition of YMJ.

\begin{tabular}{lccc}
\hline Scientific name & $\begin{array}{c}\text { Amount } \\
(\mathrm{g})\end{array}$ & Supplier & Source \\
\hline Rehmannia glutinosa & 8.0 & Omniherb & Kunwi, Korea \\
Cornus officinalis & 4.0 & Omniherb & Gurye, Korea \\
Dioscorea batatas & 4.0 & Omniherb & Kunwi, Korea \\
Paeonia suffruticosa & 3.0 & HMAX & P. R. China \\
Poria cocos & 3.0 & Omniherb & Yeongcheon, Korea \\
Alisma orientale & 3.0 & Omniherb & Imsil, Korea \\
\hline Total & 25.0 & & \\
\hline
\end{tabular}

software (version 1.24). All analytes were separated on a Phenomenex Gemini $\mathrm{C}_{18}$ column $(250 \times 4.6 \mathrm{~mm}, 5 \mu \mathrm{m}$, Torrance, $\mathrm{CA}$ ) maintained at $40^{\circ} \mathrm{C}$. The mobile phases consisted of $1.0 \%(\mathrm{v} / \mathrm{v})$ aqueous acetic acid (A) and 1.0\% (v/v) acetic acid in acetonitrile (B). The gradient flow was as follows: $5-40 \% \mathrm{~B}$ for $0-30 \mathrm{~min}$; $40-100 \% \mathrm{~B}$ for $30-40 \mathrm{~min}$; $100 \%$ $\mathrm{B}$ for $40-45 \mathrm{~min}$; and $100-5 \% \mathrm{~B}$ for $50 \mathrm{~min}$. The flow-rate was $1.0 \mathrm{~mL} / \mathrm{min}$ and the injection volume was $10 \mu \mathrm{L}$. The wavelength range of PDA detection was 190-400 nm and the detected wavelengths were monitored at $230 \mathrm{~nm}$ (morroniside, loganin, and paeoniflorin) or $280 \mathrm{~nm}$ (gallic acid, 5-HMF, and paeonol). All calibration curves were obtained by assessment of peak areas from standard solutions in the following concentration ranges: 5-HMF and morroniside, 3.13-200.00 $\mu \mathrm{g} / \mathrm{mL}$; gallic acid and loganin, $0.78-50 \mu \mathrm{g} / \mathrm{mL}$; and paeoniflorin and paeonol, $0.16-10.00 \mu \mathrm{g} / \mathrm{mL}$.

2.6. Animals. The animal studies were conducted according to the guidance of the Institutional Animal Care and Use Committee in the Korea Institute of Toxicology (KRICT) (accredited by AAALAC International, 1998) under the current Good Laboratory Practice regulations for nonclinical laboratory studies and approved by the Korea Institute of Oriental Medicine Institutional Animal Care and Use Committee (Daejeon, Korea). Specific pathogen-free Crl:CD Sprague-Dawley (SD) rats $(n=24 /$ gender $)$ were obtained from Orient Bio Co. (Seoul, Korea) and used after 2 weeks of quarantine and acclimatization. The animals were housed in a room maintained at $22 \pm 3^{\circ} \mathrm{C}$ under a relative humidity of $50 \pm 20 \%$ with artificial lighting from $08: 00$ to 20 :00 and 1215 air changes per hour. The animals were kept in stainlesssteel wire-mesh cages and allowed sterilized tap water and commercial rodent chow (PMI Nutrition International, Richmond, VA, USA) ad libitum.

2.7. Group Assignment and Treatment. Healthy male and female rats were assigned to four groups ( $n=5$ /group) using Path/Tox System 4.2.2 (Xybion Medical Systems Corp., Cedar Knolls, NJ). YMJ extract was dissolved in distilled water for injection (Choong-Wae Pharmaceutical, Ltd., Korea) and administered by oral gavage at doses of 0,500 , 1000 , and $2000 \mathrm{mg} / \mathrm{kg} /$ day for 4 weeks. Distilled water was given to the animals as the vehicle control. The daily dose (10 $\mathrm{mL} / \mathrm{kg}$ body weight) of YMJ was calculated based on the most recently recorded body weights of individual animals. 
2.8. General Observations. Clinical signs and any mortality were recorded twice a day (before and after treatment) throughout the study period. All clinical signs were recorded individually for type, observation day/time, and duration using Path/Tox System 4.2.2 (Xybion Medical Systems Corp.). The body weight of each rat was measured at the initiation of treatment and once a week during the study period. Food consumption was measured at the start of treatment and weekly throughout. Daily food consumption was determined by measuring the weights of chow supplied and remaining each day. External eye examination was carried out during the last week of treatment with an indirect binocular ophthalmoscope (IO-H, Neitz Instrument Co., Tokyo, Japan), and the appearance of the conjunctiva, sclera, cornea, lens, and iris of each eye was recorded.

2.9. Urinalysis, Hematology, and Serum Biochemistry. During the last week of treatment, urinalysis was conducted on samples collected overnight using a Multistix 10 SG (Bayer, Pittsburg, PA) and Clinitek-500 urine chemistry analyzer (Siemens Healthcare Diagnostics, Erlangen, Germany). Analysis included the volume, specific gravity (SG), $\mathrm{pH}$, protein, ketone body (KET) level, any occult blood (BLO), glucose, and bilirubin (BIL), nitrite (NIT), and urobilinogen (URO) levels, and sediment.

Animals were fasted overnight prior to blood collection or necropsy. Blood was drawn from the posterior vena cava vein with the animals under isoflurane anesthesia. Samples were collected in CBC bottles containing EDTA2K (Sewon Medical Co., Korea) and were analyzed to determine the red blood cell (RBC) count, the white blood cell (WBC) count, differential WBC count, hemoglobin concentration (HGC), hematocrit (HCT), mean corpuscular volume $(\mathrm{MCV})$, mean corpuscular hemoglobin $(\mathrm{MCH})$, mean corpuscular hemoglobin concentration (MCHC), and platelet (PLT) and reticulocyte (RET) counts using an ADVIA120 Hematology System (Bayer). Prothrombin time (PT) and activated partial thromboplastin time (APTT) were determined in blood samples treated with $3.2 \%$ sodium citrate using a coagulometer (ACL 300 plus, Instrumentation Laboratory SpA, Milan, Italy).

For serum biochemistry, blood samples were centrifuged at $3000 \mathrm{rpm}$ for $10 \mathrm{~min}$ and analyzed with an autoanalyzer (Toshiba 200FR NEO, Toshiba Co., Japan). The analysis included the concentrations of alanine aminotransferase (ALT), aspartate aminotransferase (AST), alkaline phosphatase (ALP), gamma glutamyl transpeptidase (GGT), blood urea nitrogen (BUN), creatinine (CREA), creatine kinase (CK), glucose (GLU), total cholesterol (TCHO), albumin (ALB), albumin/globulin ratio (A/G), total protein (TP), triglyceride (TG), total bilirubin (TBIL), phospholipids (PL), sodium $(\mathrm{Na})$, potassium $(\mathrm{K})$, calcium $(\mathrm{Ca})$, chloride $(\mathrm{Cl})$, and inorganic phosphorus (IP).

2.10. Necropsy. All surviving animals were anesthetized with isofluorane and euthanized by aortic exsanguination prior to necropsy. Complete gross postmortem examinations were performed on all animals. Absolute organ weights were measured and relative organ weights (organ-to-body weight ratios) were calculated for the following organs: brain, pituitary gland, adrenal gland, liver, spleen, kidneys, heart, thymus, lung, salivary gland, thyroids, testes, ovaries, epididymides, seminal vesicle, prostate, and uterus.

2.11. Cytotoxicity Assay. Twenty-three various cell lines were obtained from the American Type Culture Collection (ATCC, Rockville, MD, USA) or the Korean Cell Line Bank (Seoul, Korea). Cytotoxic effects of YMJ against the cell lines were measured using a 3-(4,5-dimethylthiazol-2-yl)-2,5diphenyl tetrazolium bromide (MTT) assay as described [10]. Cell viability was calculated as the percentage of viable cells in the drug-treated group versus untreated controls based on optical density (OD) from the following equation: Cell viability $=[\mathrm{OD}(\mathrm{YMJ})-\mathrm{OD}($ Blank $)] /[\mathrm{OD}($ Control $)-\mathrm{OD}$ (Blank) ] $\times 100$.

2.12. Statistical Analyses. Data collected during the study were examined for homogeneity of variance using Bartlett's test. When Bartlett's test indicated no significant deviation from homogeneity, a one-way analysis of variance (ANOVA) was performed at $\alpha=0.05$. When significance was noted, a multiple comparison test (Dunnett's test) was conducted to determine which pairs of groups were significantly different. Where significant deviations from homogeneity of variance were observed, a nonparametric comparison test (KruskalWallis test) was conducted. When a significant difference was observed in the Kruskal-Wallis test, Dunn's rank sum test was conducted to determine the specific pairs. Statistical analyses were performed using the Path/Tox System (ver. 4.2.2): Xybion Medical Systems Corp.). The level of significance was taken as $P<0.05$ or $P<0.01$.

\section{Results}

3.1. Characterization of the YMJ Extract. The linearity of the method was evaluated from the correlation coefficient $\left(r^{2}\right)$ of the calibration curves of each compound. We found that the six compounds showed good linearity with $r^{2} \geq$ 0.9997 in seven different concentration ranges. The limit of detection (LOD) and limit of quantification (LOQ) ranges of the six tested compounds were $0.01-0.08 \mu \mathrm{g} / \mathrm{mL}$ and $0.02-$ $0.27 \mu \mathrm{g} / \mathrm{mL}$, respectively (Table 2 ). Using optimized chromatography conditions, three-dimensional chromatograms were obtained using the HPLC-PDA detector (Figure 1). The retention times of the components were $5.95 \mathrm{~min}$ (gallic acid), $8.09 \mathrm{~min}$ (5-HMF), $13.14 \mathrm{~min}$ (morroniside), $16.15 \mathrm{~min}$ (loganin), $18.30 \mathrm{~min}$ (paeoniflorin), and $36.00 \mathrm{~min}$ (paeonol). The concentration range of the six biomarker components was $1.15-4.32 \mathrm{mg} / \mathrm{g}$ (Table 3 ).

3.2. Clinical Signs and Mortality. No treatment-related clinical sign was observed in any of the rats (Table 4). In addition, no animal death was recorded during treatment for 4 weeks (Table 5).

3.3. Body Weight Changes and Food Intake. In both male and female rats treated with YMJ, there were no significant 
TABLE 2: Regression equations, linearity, LOD, and LOQ for six standard compounds of YMJ.

\begin{tabular}{|c|c|c|c|c|c|}
\hline Analyte & Linear range $(\mu \mathrm{g} / \mathrm{mL})$ & Regression equation $^{\mathrm{a}}$ & Correlation coefficient $\left(r^{2}\right)$ & $\operatorname{LOD}^{\mathrm{b}}(\mu \mathrm{g} / \mathrm{mL})$ & $\mathrm{LOQ}^{\mathrm{c}}(\mu \mathrm{g} / \mathrm{mL})$ \\
\hline Gallic acid & $0.78-50.00$ & $y=26606.11 x-8860.81$ & 0.9998 & 0.02 & 0.06 \\
\hline 5-HMF & $3.13-200.00$ & $y=82889.12 x-2299.96$ & 0.9999 & 0.01 & 0.02 \\
\hline Morroniside & $3.13-200.00$ & $y=18597.16 x-9630.17$ & 1.0000 & 0.04 & 0.14 \\
\hline Loganin & $0.78-50.00$ & $y=16410.59 x-1454.52$ & 1.0000 & 0.05 & 0.17 \\
\hline Paeoniflorin & $0.16-10.00$ & $y=10461.75 x-4859.01$ & 0.9997 & 0.08 & 0.27 \\
\hline Paeonol & $0.16-10.00$ & $y=48319.49 x+86.82$ & 0.9999 & 0.05 & 0.16 \\
\hline
\end{tabular}

a $y$ : peak area (mAU) of compounds; $x$ : concentration $(\mu \mathrm{g} / \mathrm{mL})$ of compounds.

${ }^{\mathrm{b}}$ LOD: $3 \times$ signal-to-noise ratio.

${ }^{c}$ LOQ: $10 \times$ signal-to-noise ratio.

TABLE 3: Contents of six standard components in YMJ measured by HPLC $(n=3)$.

\begin{tabular}{|c|c|c|c|c|}
\hline Component & Mean (mg/g) & $\mathrm{SD}$ & RSD (\%) & Source \\
\hline Gallic acid & 1.70 & 0.01 & 0.31 & Paeonia suffruticosa \\
\hline 5-HMF & 4.32 & 0.01 & 0.31 & Rehmannia glutinosa \\
\hline Morroniside & 2.69 & 0.02 & 0.59 & Cornus officinalis \\
\hline Loganin & 1.63 & 0.02 & 1.14 & Cornus officinalis \\
\hline Paeoniflorin & 1.15 & 0.03 & 2.22 & Paeonia suffruticosa \\
\hline Paeonol & 1.32 & 0.00 & 0.18 & Paeonia suffruticosa \\
\hline
\end{tabular}

TABLE 4: Clinical signs in rats treated orally with YMJ.

\begin{tabular}{lcc}
\hline Group & Salivation & Scabbing \\
\hline Male rats & & \\
Vehicle control & $0 / 5$ & $0 / 5$ \\
$500 \mathrm{mg} / \mathrm{kg}$ & $0 / 5$ & $0 / 5$ \\
$1000 \mathrm{mg} / \mathrm{kg}$ & $0 / 5$ & $0 / 5$ \\
$2000 \mathrm{mg} / \mathrm{kg}$ & $0 / 5$ & $0 / 5$ \\
Female rats & & \\
Vehicle control & $0 / 5$ & $0 / 5$ \\
$500 \mathrm{mg} / \mathrm{kg}$ & $0 / 5$ & $0 / 5$ \\
$1000 \mathrm{mg} / \mathrm{kg}$ & $0 / 5$ & $0 / 5$ \\
$2000 \mathrm{mg} / \mathrm{kg}$ & $0 / 5$ & $0 / 5$ \\
\hline
\end{tabular}

differences in body weight between vehicle control and YJMtreated groups (Figure 2). No significant differences in food consumption were observed between vehicle control and treatment group for either gender (Figure 3).

3.4. Necropsy. Absolute organ weights were measured and the relative organ weight (organ weight/fasted body weight) was calculated for 15 different organs (Table 6). In male rats, a decrease in the absolute weight of the epididymides was noted at 1000 and $2000 \mathrm{mg} / \mathrm{kg} /$ day (one-way ANOVA; $P<$ $0.05)$. In contrast, the absolute weights of all tested organs had no significant differences between vehicle control and YMJ-treated female rats (Table 6). In addition, no treatmentrelated gross finding was observed in the necropsy performed at euthanasia for both genders (data not shown).

3.5. Hematology, Serum Biochemistry, and Urinalysis. No significant differences in hematology test outcomes were found between vehicle control and YMJ-treated male rats (Table 7). In contrast, PT was significantly reduced in female rats at 1000 and $2000 \mathrm{mg} / \mathrm{kg} /$ day (one-way ANOVA; $P<0.01$ and $P<0.05$, resp.). As shown in Table 8 , serum biochemical analysis showed that the $\mathrm{Na}$ concentration was increased in YMJ-treated male rats at $1000 \mathrm{mg} / \mathrm{kg} /$ day (Kruskal-Wallis test; $P<0.05)$ whereas the creatine level was decreased in YMJ-fed female rats at 500 and $1000 \mathrm{mg} / \mathrm{kg} /$ day (KruskalWallis test; $P<0.05$ and $P<0.01$, resp.). There were no significant differences in urinalysis values between the vehicle-only control and treatment groups (data not shown).

3.6. Cytotoxicity. Cytotoxicity of YMJ was evaluated against 23 different cell lines. Cells were treated with various concentrations $(0,10,20,50,100$, or $200 \mu \mathrm{g} / \mathrm{mL})$ of YMJ extract for $24 \mathrm{~h}$. As shown in Table 9, the cell viability was not significantly altered in any of the tested cell lines including SH-SY5Y, SK-N-SH (neuroblastomas), U-373 MG, U-87 MG (glioblastomas), HepG2, Hep3B (hepatocarcinomas), Clone M-3, B16F10 (melanomas), HEK-293, NRK52 (kidney cells), 3T3-L1, NIH3T3 (fibroblasts), HIT-T15 (pancreatic cells), HL60, RBL-1 (leukemias), HT-29 (colon cancer), MCF-7 (breast cancer), $\mathrm{HaCaT}$ (keratinocytes), $\mathrm{PC1} 2$ (phechromocytomas), LNCaP (prostate cancer), BEAS-2B (bronchial epithelial cells), and AGS (gastric adenocarcinoma) up to $200 \mu \mathrm{g} / \mathrm{mL}$ in all tested cell lines.

\section{Discussion}

YMJ is a well-known herbal formula that has long been used in CAM for the treatment of renal diseases and diabetes mellitus. Several studies have provided scientific evidence on the biological activities of YMJ against renal diseases, diabetes, and bone diseases. Thus, treatment with YMJ ameliorated 


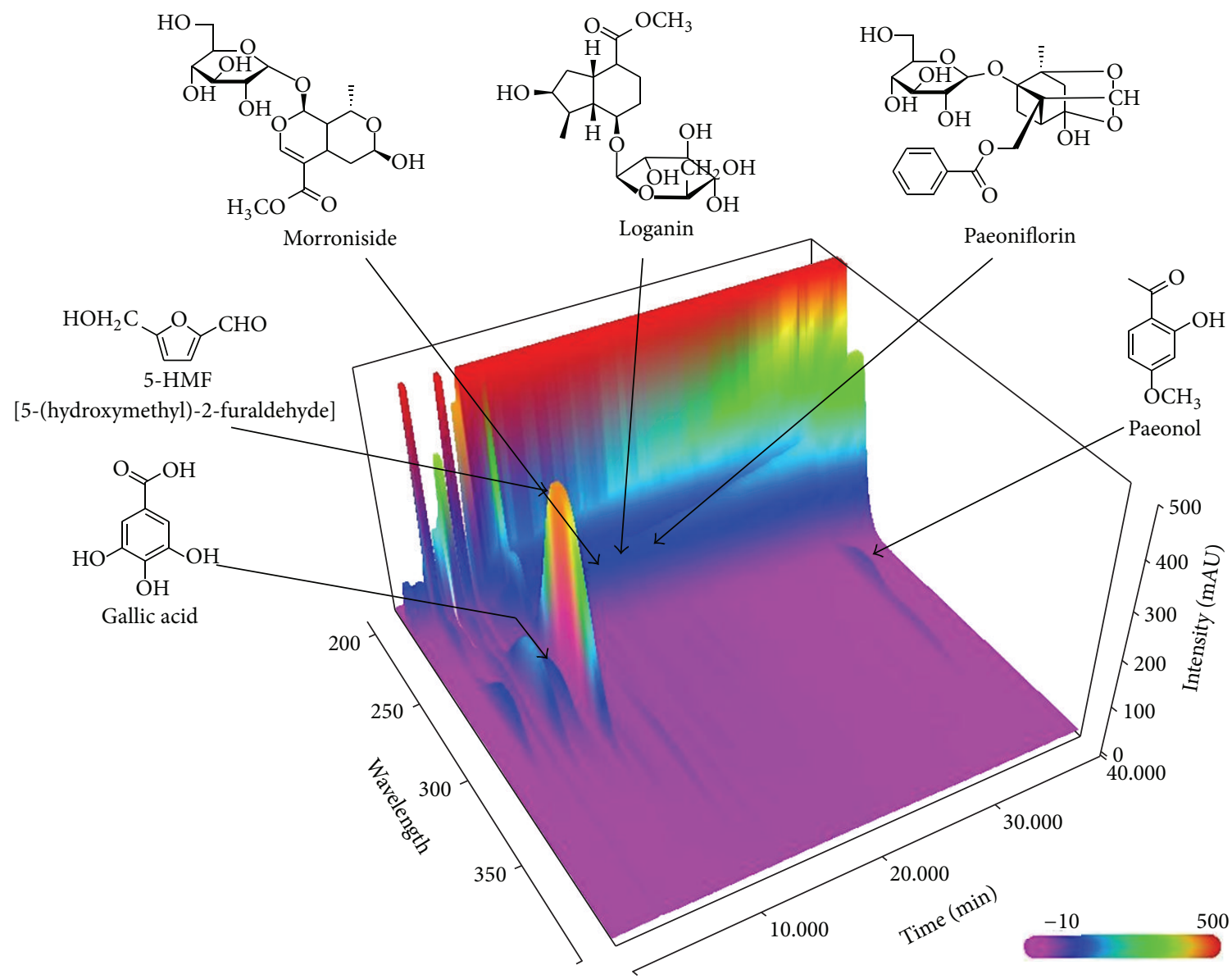

Figure 1: Three-dimensional chromatogram of YMJ by HPLC-PDA. Column: Gemini $\mathrm{C}_{18}(250 \times 4.6 \mathrm{~mm}, 5 \mu \mathrm{m})$; mobile phase: $1.0 \%$ (v/v) acetic acid in water (A) and 1.0\% (v/v) acetic acid in acetonitrile (B) (5-40\% B for 0-30 min, 40-100\% B for 30-40 min, 100\% B for 40-45 min, and $100-5 \%$ B for $50 \mathrm{~min}$ ); flow rate: $1.0 \mathrm{~mL} / \mathrm{min}$; retention time: $5.95 \mathrm{~min}$ (gallic acid), $8.09 \mathrm{~min}$ (5-HMF), 13.14 min (morroniside), $16.15 \mathrm{~min}$ (loganin), $18.30 \mathrm{~min}$ (paeoniflorin), and $36.00 \mathrm{~min}$ (paeonol).

TABLE 5: Mortality in rats treated orally with YMJ.

\begin{tabular}{|c|c|c|c|c|c|c|}
\hline \multirow{2}{*}{ Dose $(\mathrm{mg} / \mathrm{kg})$} & \multicolumn{5}{|c|}{ Dosing phase } & \multirow{2}{*}{ Final mortality } \\
\hline & 1 day & $\leq 7$ days & $\leq 14$ days & $\leq 21$ days & $\leq 29$ days & \\
\hline 0 & 0 & 0 & 0 & 0 & 0 & $0 / 5$ \\
\hline 500 & 0 & 0 & 0 & 0 & 0 & $0 / 5$ \\
\hline 1000 & 0 & 0 & 0 & 0 & 0 & $0 / 5$ \\
\hline 2000 & 0 & 0 & 0 & 0 & 0 & $0 / 5$ \\
\hline
\end{tabular}

renal defects in rats with ischemia/reperfusion-induced acute renal failure (ARF) [11]. YMJ markedly restored renal functional parameters including creatine clearance, urinary sodium excretion, urinary osmolality, and solute-free reabsorption with lowering the expression of renal aquaporin 2 (AQP2) and heme oxygenase 1 (HO-1). Additionally, YMJ pills induced apoptosis by regulating the expression of the bcl-2/bax genes at the transcriptional level in the pancreas of Otsuka Long-Evans Tokushima fatty (OLETF) rats with type 2 diabetes [10]. Shim et al. reported the therapeutic potential of YMJ in treating bone diseases by suppressing receptor activator for nuclear factor- $\kappa \mathrm{B}$ ligand- (RANK-) induced osteoclast differentiation [3]. Moreover, Wang et al. reported the combinatorial effect of YMJ and antihypertensive drugs on the improvement of blood pressure and symptoms, suggesting a new integrative medicine therapy for patients with essential hypertension patients [12].

Given the efficacy of YMJ, information on its safety as a medicine should be evaluated carefully because YMJ is a mixture of six different herbs as well as several different phytochemicals. Previously, we reported on the acute and subchronic toxicity as well as genotoxicity of YMJ in an animal model. We found that YMJ had no acute and subchronic toxicity or genotoxicity and its no-observed-adverse-effectlevel (NOAEL) is $2000 \mathrm{mg} / \mathrm{kg} /$ day $[13,14]$. However, there has been no report on the subacute toxicity of YMJ. Therefore, 


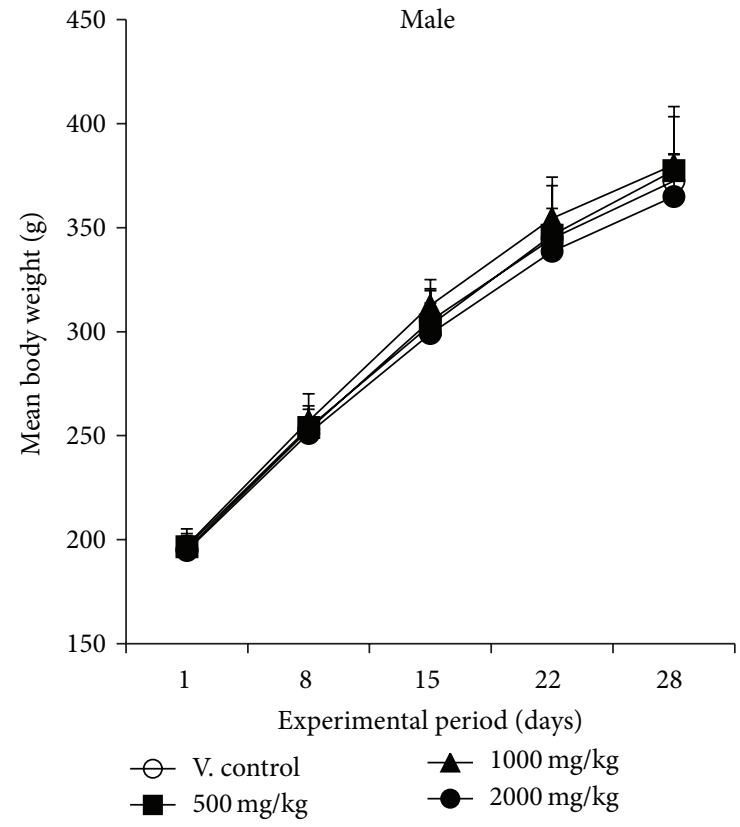

(a)

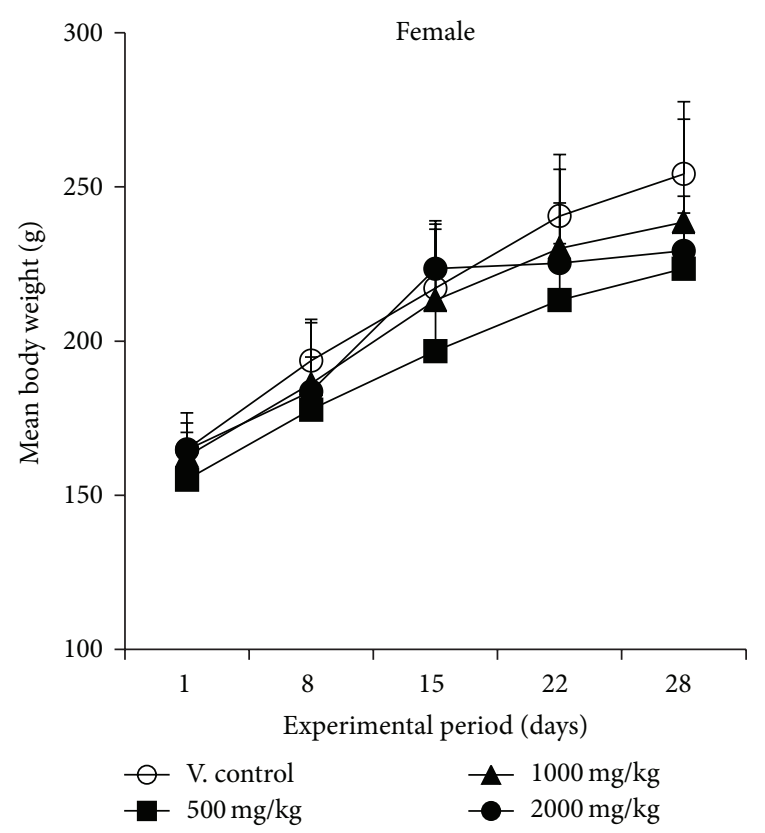

(b)

Figure 2: Mean body weight changes of male (a) and female (b) rats treated with YMJ. Healthy male and female rats were assigned to four groups ( $n=5$ /group) using Path/Tox System 4.2.2. YMJ extract was dissolved in distilled water for injection and administered by oral gavage

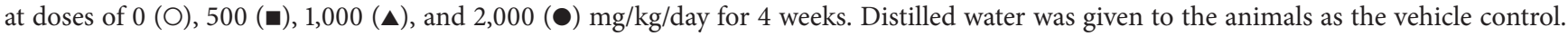
Values are presented as the mean \pm SD.

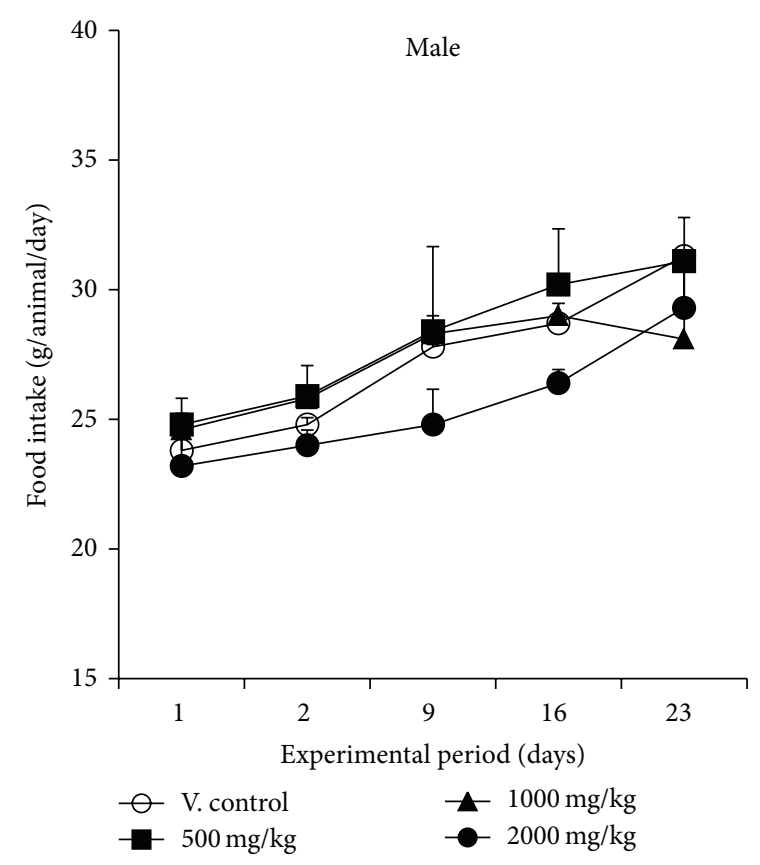

(a)

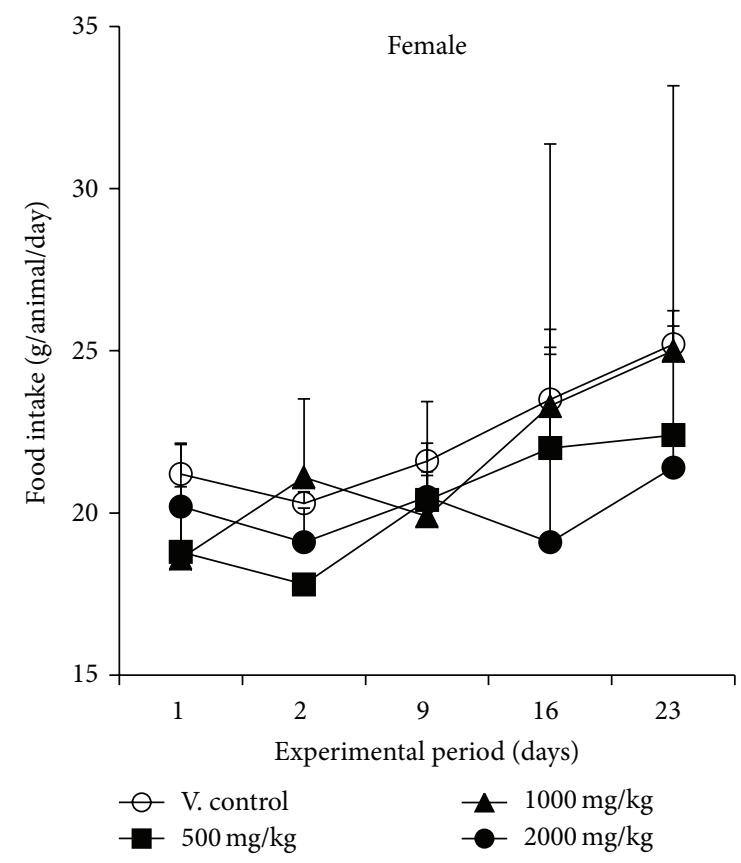

(b)

FiguRE 3: Food intake in male (a) and female (b) rats treated with YMJ. Healthy male and female rats were assigned to four groups $(n=$ 5/group) using Path/Tox System 4.2.2. YMJ extract was dissolved in distilled water for injection and administered by oral gavage at doses of $0(\mathrm{O}), 500(\mathbf{\square}), 1,000(\mathbf{\Delta})$, and 2,000 (๑) $\mathrm{mg} / \mathrm{kg} /$ day for 4 weeks. Distilled water was given to the animals as the vehicle control. Values are the mean \pm SD. ${ }^{*} P<0.05$ versus vehicle control group (V. control). 
TABLE 6: Absolute organ weights in rats treated with YMJ for 4 weeks.

\begin{tabular}{|c|c|c|c|c|}
\hline Dose (mg/kg/day) & 0 & 500 & 1000 & 2000 \\
\hline \multicolumn{5}{|l|}{ Male rats } \\
\hline Brain & $1.919 \pm 0.0808$ & $1.880 \pm 0.1136$ & $1.949 \pm 0.0403$ & $1.945 \pm 0.0833$ \\
\hline Pituitary gland & $0.010 \pm 0.0026$ & $0.010 \pm 0.0023$ & $0.010 \pm 0.0022$ & $0.009 \pm 0.0028$ \\
\hline Liver & $10.102 \pm 0.5764$ & $10.403 \pm 0.7475$ & $10.483 \pm 0.1410$ & $10.234 \pm 1.5110$ \\
\hline Spleen & $0.607 \pm 0.0700$ & $0.640 \pm 0.0979$ & $0.725 \pm 0.0848$ & $0.643 \pm 0.1482$ \\
\hline Heart & $1.180 \pm 0.0643$ & $1.172 \pm 0.1247$ & $1.173 \pm 0.0273$ & $1.110 \pm 0.1174$ \\
\hline Thymus & $0.558 \pm 0.1072$ & $0.600 \pm 0.0548$ & $0.492 \pm 0.0949$ & $0.550 \pm 0.1330$ \\
\hline Salivary glands & $0.625 \pm 0.0561$ & $0.581 \pm 0.0779$ & $0.593 \pm 0.0475$ & $0.547 \pm 0.0688$ \\
\hline Seminal vesicle & $1.031 \pm 0.1515$ & $1.089 \pm 0.1220$ & $0.944 \pm 0.1084$ & $0.994 \pm 0.1193$ \\
\hline Prostate & $0.468 \pm 0.1143$ & $0.405 \pm 0.1367$ & $0.405 \pm 0.0543$ & $0.402 \pm 0.0394$ \\
\hline Kidneys & $2.501 \pm 0.1742$ & $2.506 \pm 0.1711$ & $2.535 \pm 0.0996$ & $2.498 \pm 0.2781$ \\
\hline Adrenal glands & $0.052 \pm 0.0073$ & $0.046 \pm 0.0044$ & $0.049 \pm 0.0073$ & $0.047 \pm 0.0060$ \\
\hline Testes & $3.237 \pm 0.2174$ & $2.971 \pm 0.2266$ & $3.177 \pm 0.1425$ & $3.023 \pm 0.1289$ \\
\hline Epididymides & $0.911 \pm 0.0681$ & $0.893 \pm 0.0425$ & $0.831 \pm 0.0345^{*}$ & $0.815 \pm 0.0289^{*}$ \\
\hline Lung & $1.317 \pm 0.0284$ & $1.313 \pm 0.1563$ & $1.359 \pm 0.0700$ & $1.278 \pm 0.1018$ \\
\hline Thyroid/parathyroid & $0.016 \pm 0.0053$ & $0.015 \pm 0.0046$ & $0.014 \pm 0.0025$ & $0.015 \pm 0.0047$ \\
\hline \multicolumn{5}{|l|}{ Female rats } \\
\hline Brain & $1.780 \pm 0.0734$ & $1.740 \pm 0.0536$ & $1.825 \pm 0.0755$ & $1.758 \pm 0.0998$ \\
\hline Pituitary gland & $0.010 \pm 0.0034$ & $0.010 \pm 0.0025$ & $0.010 \pm 0.0023$ & $0.011 \pm 0.0017$ \\
\hline Liver & $7.387 \pm 0.7843$ & $6.397 \pm 0.5466$ & $7.076 \pm 1.3626$ & $6.948 \pm 0.5587$ \\
\hline Spleen & $0.504 \pm 0.0368$ & $0.451 \pm 0.0938$ & $0.511 \pm 0.1144$ & $0.543 \pm 0.0822$ \\
\hline Heart & $0.889 \pm 0.1013$ & $0.838 \pm 0.0615$ & $0.864 \pm 0.1392$ & $0.825 \pm 0.0920$ \\
\hline Thymus & $0.455 \pm 0.0396$ & $0.433 \pm 0.0476$ & $0.447 \pm 0.1072$ & $0.460 \pm 0.0314$ \\
\hline Salivary glands & $0.426 \pm 0.0514$ & $0.390 \pm 0.0262$ & $0.418 \pm 0.0558$ & $0.376 \pm 0.0244$ \\
\hline Kidneys & $1.814 \pm 0.1545$ & $1.731 \pm 0.1631$ & $1.880 \pm 0.2300$ & $1.684 \pm 0.1485$ \\
\hline Adrenal glands & $0.066 \pm 0.0088$ & $0.059 \pm 0.0090$ & $0.067 \pm 0.0108$ & $0.068 \pm 0.0123$ \\
\hline Ovaries & $0.087 \pm 0.0092$ & $0.079 \pm 0.0223$ & $0.092 \pm 0.0311$ & $0.088 \pm 0.0194$ \\
\hline Lung & $1.094 \pm 0.0422$ & $1.042 \pm 0.0847$ & $1.034 \pm 0.1157$ & $1.090 \pm 0.1078$ \\
\hline Thyroid/parathyroid & $0.012 \pm 0.0048$ & $0.011 \pm 0.0025$ & $0.015 \pm 0.0023$ & $0.014 \pm 0.0037$ \\
\hline Uterus/cervix & $0.614 \pm 0.3916$ & $0.458 \pm 0.1359$ & $0.617 \pm 0.2779$ & $0.402 \pm 0.0820$ \\
\hline
\end{tabular}

Values are presented as the mean \pm SD.

${ }^{*} P<0.05$ compared with the vehicle control.

here we evaluated the toxicity of YMJ over 4 weeks to test its subacute toxicity in male or female Crl:CD (SD) rats.

We observed that YMJ did not significantly change clinical signs, body weight, or food intake in either male or female rats. The Society of Toxicologic Pathology (STP) recommends the evaluation of organ weights in general toxicology studies [15]. However, YMJ treatment decreased the absolute weights of both epididymides at 1000 and $2000 \mathrm{mg} / \mathrm{kg} /$ day in male rats. Epididymal weight changes are a sensitive indicator of decreased sperm production and can reflect edema or inflammation. Thus, epididymal weight should be measured routinely for multidose rat toxicology tests using GLP [16]. However, the changes in epididymal weights caused by YMJ treatment were not severe and not dose-dependent and were considered to be in the normal physiological range [17].

In terms of hematological data, YMJ administration significantly decreased the PT at 1000 and $2000 \mathrm{mg} / \mathrm{kg} /$ day after female rats. A prolonged PT is an early indicator of renal damage in poisoning with metabolic toxins [18]. The reference range for PT is usually less than $20 \mathrm{sec}$ depending on the assay protocol [19]. In our study, the PT values of YMJ-treated rats were 13.2 and $13.4 \mathrm{sec}$ at 1000 and $2000 \mathrm{mg} / \mathrm{kg}$, respectively, namely, in the normal range. Serum biochemical values are also important parameters in toxicology studies [20]. We found that YMJ treatment increased the $\mathrm{Na}$ concentration at $1000 \mathrm{mg} / \mathrm{kg} /$ day in male rats and decreased the creatine levels at 500 and $1000 \mathrm{mg} / \mathrm{kg} /$ day in female rats. Serum Na concentration reflects the pump that maintains the constancy of its extracellular concentration and creatine content reflects renal functional capacity [21]. Changes in $\mathrm{Na}$ and creatine contents of the serum in our study did not exceed the normal range (Na: $143-156 \mathrm{mEq} / \mathrm{L}$, creatine: $0.2-0.8 \mathrm{mg} / \mathrm{dL}$ ) [22].

Thus, 4-week repeated oral administration of YMJ caused no subacute toxic effects in rats. Consistent with the results of other toxicity studies $[23,24]$, the NOAEL was estimated to be $2000 \mathrm{mg} / \mathrm{kg} /$ day. In the pharmacokinetic aspect, the metabolism rate in small animals including mouse and rat is faster than in humans [25]. As we previously reported [13], 
TABLE 7: Hematological values of animals treated with YMJ for 4 weeks.

\begin{tabular}{|c|c|c|c|c|}
\hline Dose (mg/kg/day) & 0 & 500 & 1000 & 2000 \\
\hline \multicolumn{5}{|l|}{ Male rats } \\
\hline $\operatorname{WBC}\left(10^{3} / \mu \mathrm{L}\right)$ & $13.17 \pm 3.558$ & $11.65 \pm 3.265$ & $14.15 \pm 3.582$ & $10.30 \pm 3.453$ \\
\hline Reticulocytes (\%) & $2.7 \pm 0.33$ & $2.4 \pm 0.21$ & $2.5 \pm 0.31$ & $2.6 \pm 0.56$ \\
\hline Neutrophils (\%) & $15.72 \pm 4.759$ & $13.54 \pm 3.412$ & $11.46 \pm 3.400$ & $13.06 \pm 2.859$ \\
\hline Lymphocytes (\%) & $78.9 \pm 5.44$ & $81.1 \pm 2.97$ & $83.0 \pm 4.06$ & $81.6 \pm 2.72$ \\
\hline Eosinophils (\%) & $0.9 \pm 0.40$ & $0.8 \pm 0.18$ & $0.8 \pm 0.24$ & $0.9 \pm 0.57$ \\
\hline Monocytes (\%) & $3.1 \pm 0.54$ & $3.2 \pm 0.85$ & $3.2 \pm 0.97$ & $3.1 \pm 0.61$ \\
\hline Basophils (\%) & $0.3 \pm 0.04$ & $0.3 \pm 0.07$ & $0.2 \pm 0.00$ & $0.3 \pm 0.13$ \\
\hline Large unstained cells (\%) & $1.2 \pm 0.33$ & $1.0 \pm 0.23$ & $1.3 \pm 0.52$ & $1.1 \pm 0.31$ \\
\hline $\operatorname{RBC}\left(10^{6} / \mu \mathrm{L}\right)$ & $7.92 \pm 0.182$ & $8.02 \pm 0.458$ & $7.75 \pm 0.149$ & $7.87 \pm 0.321$ \\
\hline Hemoglobin (g/dL) & $15.5 \pm 0.37$ & $15.5 \pm 0.58$ & $15.4 \pm 0.25$ & $15.6 \pm 0.55$ \\
\hline Hematocrit (\%) & $46.3 \pm 1.09$ & $46.3 \pm 1.70$ & $45.8 \pm 0.60$ & $46.5 \pm 1.49$ \\
\hline MCV (fL) & $58.4 \pm 0.86$ & $57.8 \pm 1.65$ & $59.2 \pm 1.50$ & $59.2 \pm 1.71$ \\
\hline $\mathrm{MCH}(\mathrm{pg})$ & $19.5 \pm 0.27$ & $19.3 \pm 0.74$ & $20.0 \pm 0.57$ & $19.9 \pm 0.30$ \\
\hline $\mathrm{MCHC}(\mathrm{g} / \mathrm{dL})$ & $33.5 \pm 0.62$ & $33.4 \pm 0.38$ & $33.7 \pm 0.40$ & $33.6 \pm 0.60$ \\
\hline Platelet $\left(10^{3} / \mu \mathrm{L}\right)$ & $1312 \pm 107.8$ & $1112 \pm 89.7$ & $1258 \pm 168.9$ & $1192 \pm 132.3$ \\
\hline $\mathrm{PT}(\mathrm{sec})$ & $13.7 \pm 0.13$ & $13.7 \pm 0.48$ & $13.6 \pm 0.19$ & $13.9 \pm 0.25$ \\
\hline \multicolumn{5}{|l|}{ Female rats } \\
\hline $\mathrm{WBC}\left(10^{3} / \mu \mathrm{L}\right)$ & $9.28 \pm 1.902$ & $8.15 \pm 1.819$ & $8.79 \pm 1.528$ & $8.57 \pm 0.896$ \\
\hline Reticulocytes (\%) & $2.2 \pm 0.35$ & $1.9 \pm 0.49$ & $2.6 \pm 0.85$ & $2.0 \pm 0.47$ \\
\hline Neutrophils (\%) & $15.82 \pm 4.190$ & $15.70 \pm 6.911$ & $12.10 \pm 4.552$ & $19.00 \pm 10.368$ \\
\hline Lymphocytes (\%) & $78.7 \pm 5.08$ & $78.9 \pm 6.51$ & $82.7 \pm 3.22$ & $75.8 \pm 10.93$ \\
\hline Eosinophils (\%) & $0.9 \pm 0.19$ & $1.2 \pm 0.24$ & $1.2 \pm 0.64$ & $1.2 \pm 0.15$ \\
\hline Monocytes (\%) & $3.1 \pm 1.17$ & $3.0 \pm 1.68$ & $2.4 \pm 0.92$ & $2.8 \pm 0.93$ \\
\hline Basophils (\%) & $0.3 \pm 0.09$ & $0.2 \pm 0.12$ & $0.3 \pm 0.04$ & $0.2 \pm 0.05$ \\
\hline Large unstained cells (\%) & $1.2 \pm 0.15$ & $1.0 \pm 0.25$ & $1.3 \pm 0.48$ & $0.9 \pm 0.32$ \\
\hline $\operatorname{RBC}\left(10^{6} / \mu \mathrm{L}\right)$ & $7.63 \pm 0.187$ & $7.76 \pm 0.313$ & $7.72 \pm 0.287$ & $7.76 \pm 0.224$ \\
\hline Hemoglobin (g/dL) & $15.1 \pm 0.29$ & $15.2 \pm 0.49$ & $15.3 \pm 0.23$ & $15.3 \pm 0.30$ \\
\hline Hematocrit (\%) & $44.6 \pm 0.38$ & $44.8 \pm 1.25$ & $45.4 \pm 0.82$ & $44.6 \pm 0.76$ \\
\hline MCV (fL) & $58.5 \pm 1.41$ & $57.8 \pm 1.21$ & $58.9 \pm 2.99$ & $57.5 \pm 1.08$ \\
\hline $\mathrm{MCH}(\mathrm{pg})$ & $19.7 \pm 0.49$ & $19.7 \pm 0.58$ & $19.8 \pm 0.83$ & $19.8 \pm 0.47$ \\
\hline MCHC (g/dL) & $33.7 \pm 0.40$ & $34.0 \pm 0.61$ & $33.7 \pm 0.57$ & $34.4 \pm 0.24$ \\
\hline Platelet $\left(10^{3} / \mu \mathrm{L}\right)$ & $1157 \pm 74.5$ & $1329 \pm 119.5$ & $1158 \pm 71.5$ & $1223 \pm 127.7$ \\
\hline PT (sec) & $14.0 \pm 0.29$ & $13.8 \pm 0.41$ & $13.2 \pm 0.18^{* *}$ & $13.4 \pm 0.51^{*}$ \\
\hline
\end{tabular}

MCV, mean corpuscular volume; $\mathrm{MCH}$, mean corpuscular hemoglobin; $\mathrm{MCHC}$, mean corpuscular hemoglobin concentration; PT, prothrombin time.

Values are presented as the mean $\pm \mathrm{SD}$.

${ }^{*} P<0.05$ and ${ }^{* *} P<0.01$ compared with the vehicle control group.

the equivalent dose of YMJ in rats converted from its single dose in humans was $1,329 \mathrm{mg}$ according to van Miert [26], which is a value less than the NOAEL (2000 $\mathrm{mg} / \mathrm{kg}$ in rats). The single administration dose of YMJ in human is $46.875 \mathrm{~g}$ dried herb [1], which is equivalent to $12.656 \mathrm{~g}$ of the extract (yield $=27.0 \%$ of the raw material).

Furthermore, we tested the cytotoxicity of YMJ against 23 different cell lines (Table 9). The cells were treated with YMJ extract at a concentration range of $1-200 \mu \mathrm{g} / \mathrm{mL}$ for $24 \mathrm{~h}$. YMJ had no effect on the viability of several cancer cell lines including neuroblastomas (SH-SY5Y and SK-N-SH), glioblastomas (U-373 MG and U-87 MG), hepatocarcinomas (HepG2 and Hep3B), melanomas (Clone M-3 and B16F10), leukemias (HL-60 and RBL-1), colon cancer (HT-29), breast cancer (MCF-7), phechromocytomas (PC12), prostate cancer (LNCaP), or gastric adenocarcinomas (AGS). Nor did YMJ treatment induce any toxicity in kidney cells (HEK-293 and NRK52), fibroblasts (3T3-L1 and NIH3T3), pancreatic cells (HIT-T15), keratinocytes (HaCaT), and bronchial epithelial cells (BEAS-2B). These results could be used when evaluating the biological activity of YMJ using in vitro assays.

In conclusion, our findings provide information on the safety of YMJ in vitro and in vivo. Using a model of SD rats fed with YMJ for 4 weeks, we demonstrated that YMJ did not have severe or specific adverse effects in either male or female rats at doses of up to $2000 \mathrm{mg} / \mathrm{kg} /$ day. Our in vitro cytotoxicity 
TABLE 8: Serum biochemical values of animals treated with YMJ for 4 weeks.

\begin{tabular}{|c|c|c|c|c|}
\hline Dose (mg/kg/day) & 0 & 500 & 1000 & 2000 \\
\hline \multicolumn{5}{|l|}{ Male rats } \\
\hline Glucose (mg/dL) & $115.9 \pm 13.28$ & $102.8 \pm 9.00$ & $102.3 \pm 18.22$ & $117.3 \pm 17.18$ \\
\hline BUN (mg/dL) & $10.9 \pm 0.84$ & $12.2 \pm 0.66$ & $11.7 \pm 1.90$ & $12.4 \pm 1.35$ \\
\hline Creatinine (mg/dL) & $0.49 \pm 0.057$ & $0.48 \pm 0.015$ & $0.52 \pm 0.055$ & $0.51 \pm 0.040$ \\
\hline Total protein $(\mathrm{g} / \mathrm{dL})$ & $6.25 \pm 0.173$ & $6.18 \pm 0.308$ & $6.41 \pm 0.304$ & $6.33 \pm 0.045$ \\
\hline Albumin (g/dL) & $4.30 \pm 0.084$ & $4.28 \pm 0.169$ & $4.38 \pm 0.105$ & $4.36 \pm 0.067$ \\
\hline Albumin/globulin ratio & $2.21 \pm 0.094$ & $2.26 \pm 0.121$ & $2.18 \pm 0.204$ & $2.23 \pm 0.145$ \\
\hline Total cholesterol (mg/dL) & $61.4 \pm 8.99$ & $57.8 \pm 9.28$ & $60.6 \pm 12.30$ & $60.8 \pm 10.85$ \\
\hline Triglycerides (mg/dL) & $44.7 \pm 16.71$ & $49.1 \pm 18.69$ & $44.5 \pm 14.46$ & $49.4 \pm 22.12$ \\
\hline Phospholipid (mg/dL) & $98 \pm 10.7$ & $92 \pm 9.9$ & $95 \pm 13.9$ & $95 \pm 19.4$ \\
\hline AST (IU/L) & $108.1 \pm 8.07$ & $116.7 \pm 14.85$ & $121.2 \pm 20.65$ & $114.2 \pm 14.18$ \\
\hline ALT (IU/L) & $28.8 \pm 4.09$ & $31.5 \pm 4.90$ & $35.9 \pm 12.72$ & $27.2 \pm 1.25$ \\
\hline Total bilirubin (mg/dL) & $0.096 \pm 0.0113$ & $0.105 \pm 0.0092$ & $0.112 \pm 0.0116$ & $0.098 \pm 0.0067$ \\
\hline ALP (IU/L) & $449.6 \pm 34.20$ & $491.2 \pm 84.72$ & $476.0 \pm 28.92$ & $479.6 \pm 94.04$ \\
\hline Creatine kinase (IU/L) & $527 \pm 124.0$ & $639 \pm 111.1$ & $656 \pm 168.0$ & $637 \pm 217.8$ \\
\hline $\mathrm{Ca}(\mathrm{mg} / \mathrm{dL})$ & $10.89 \pm 0.203$ & $10.55 \pm 0.376$ & $10.78 \pm 0.425$ & $10.77 \pm 0.479$ \\
\hline IP (mg/dL) & $10.43 \pm 0.907$ & $9.86 \pm 1.044$ & $10.04 \pm 1.174$ & $9.72 \pm 0.924$ \\
\hline $\mathrm{Na}(\mathrm{mmol} / \mathrm{L})$ & $144 \pm 0.9$ & $145 \pm 0.7$ & $146 \pm 1.5^{*}$ & $146 \pm 0.7$ \\
\hline $\mathrm{K}(\mathrm{mmol} / \mathrm{L})$ & $7.52 \pm 0.800$ & $6.51 \pm 1.190$ & $5.80 \pm 1.195$ & $6.49 \pm 1.255$ \\
\hline $\mathrm{Cl}(\mathrm{mmol} / \mathrm{L})$ & $103 \pm 1.9$ & $103 \pm 1.1$ & $103 \pm 1.3$ & $104 \pm 2.1$ \\
\hline GGT (IU/L) & $1.03 \pm 1.460$ & $0.15 \pm 0.143$ & $0.15 \pm 0.143$ & $0.44 \pm 0.615$ \\
\hline \multicolumn{5}{|l|}{ Female rats } \\
\hline Glucose (mg/dL) & $110.6 \pm 17.45$ & $105.5 \pm 15.58$ & $118.9 \pm 12.20$ & $91.1 \pm 7.68$ \\
\hline BUN (mg/dL) & $15.76 \pm 2.25$ & $13.6 \pm 0.82$ & $14.0 \pm 2.02$ & $14.4 \pm 1.43$ \\
\hline Creatinine (mg/dL) & $0.60 \pm 0.011$ & $0.55 \pm 0.007^{*}$ & $0.54 \pm 0.011^{* *}$ & $0.59 \pm 0.029$ \\
\hline Total protein $(\mathrm{g} / \mathrm{dL})$ & $6.76 \pm 0.451$ & $6.65 \pm 0.255$ & $6.82 \pm 0.224$ & $6.76 \pm 0.381$ \\
\hline Albumin (g/dL) & $4.58 \pm 0.243$ & $4.65 \pm 0.136$ & $4.65 \pm 0.118$ & $4.61 \pm 0.205$ \\
\hline Albumin/globulin ratio & $2.10 \pm 0.114$ & $2.34 \pm 0.120$ & $2.15 \pm 0.103$ & $2.16 \pm 0.168$ \\
\hline Total cholesterol (mg/dL) & $70.0 \pm 9.72$ & $70.0 \pm 12.98$ & $72.6 \pm 13.87$ & $75.8 \pm 21.81$ \\
\hline Triglycerides (mg/dL) & $36.5 \pm 6.90$ & $34.3 \pm 3.47$ & $30.2 \pm 7.55$ & $31.6 \pm 7.08$ \\
\hline Phospholipid (mg/dL) & $123 \pm 20.2$ & $124 \pm 15.1$ & $127 \pm 21.5$ & $129 \pm 24.9$ \\
\hline AST (IU/L) & $109.3 \pm 17.78$ & $108.7 \pm 20.14$ & $101.1 \pm 10.93$ & $116.5 \pm 24.99$ \\
\hline ALT (IU/L) & $27.1 \pm 4.47$ & $25.9 \pm 2.50$ & $24.4 \pm 4.06$ & $27.0 \pm 3.28$ \\
\hline Total bilirubin (mg/dL) & $0.112 \pm 0.0101$ & $0.116 \pm 0.0111$ & $0.118 \pm 0.0251$ & $0.117 \pm 0.0178$ \\
\hline ALP (IU/L) & $217.9 \pm 20.72$ & $244.9 \pm 15.87$ & $261.3 \pm 61.05$ & $290.1 \pm 99.47$ \\
\hline Creatine kinase (IU/L) & $498 \pm 172.4$ & $518 \pm 166.8$ & $387 \pm 93.7$ & $520 \pm 233.7$ \\
\hline $\mathrm{Ca}(\mathrm{mg} / \mathrm{dL})$ & $10.82 \pm 0.444$ & $10.80 \pm 0.344$ & $11.14 \pm 0.316$ & $10.97 \pm 0.418$ \\
\hline IP (mg/dL) & $8.30 \pm 0.427$ & $7.84 \pm 0.926$ & $8.49 \pm 0.770$ & $8.80 \pm 0.329$ \\
\hline $\mathrm{Na}(\mathrm{mmol} / \mathrm{L})$ & $143 \pm 1.6$ & $144 \pm 1.3$ & $145 \pm 1.1$ & $143 \pm 0.8$ \\
\hline $\mathrm{K}(\mathrm{mmol} / \mathrm{L})$ & $6.06 \pm 0.394$ & $6.23 \pm 1.241$ & $6.52 \pm 0.350$ & $6.86 \pm 0.573$ \\
\hline $\mathrm{Cl}(\mathrm{mmol} / \mathrm{L})$ & $104 \pm 2.4$ & $105 \pm 1.3$ & $104 \pm 1.3$ & $103 \pm 1.1$ \\
\hline GGT (IU/L) & $0.92 \pm 0.579$ & $0.67 \pm 0.524$ & $0.99 \pm 0.603$ & $0.99 \pm 0.374$ \\
\hline
\end{tabular}

ALP, alkaline phosphatase; AST, aspartate aminotransferase; ALT, alkaline phosphatase; BUN, blood urea nitrogen.

Values are presented as mean \pm SD.

${ }^{*} P<0.05$ and ${ }^{* *} P<0.01$ compared with the vehicle control group.

study also showed that YMJ had no significant effects on the viability of 23 different cell lines. Our data and other information on YMJ safety could be valuable to establish preclinical and clinical studies for YMJ or its related herbal formulas. Furthermore, many studies have reported that the six herbal components (Rehmannia glutinosa, Cornus officinalis, Dioscorea batatas, Paeonia suffruticosa, Poria cocos, and Alisma orientale) have biological potential as preventive or therapeutic agents. Therefore, we consider that the efficacy of YMJ probably results from synergistic interactions between 
TABLE 9: Cytotoxicity of YMJ against various cell lines.

\begin{tabular}{|c|c|c|c|c|c|c|c|}
\hline \multirow{2}{*}{ Cell line } & \multirow{2}{*}{ Origin } & \multicolumn{6}{|c|}{ Concentration $(\mu \mathrm{g} / \mathrm{mL})$} \\
\hline & & 0 & 10 & 20 & 50 & 100 & 200 \\
\hline SH-SY5Y & Human, neuroblastoma & $100 \pm 1.84$ & $97 \pm 1.69$ & $98 \pm 0.92$ & $96 \pm 1.17$ & $100 \pm 2.40$ & $101 \pm 0.60$ \\
\hline Clone M-3 & Mouse, melanoma & $100 \pm 9.99$ & $95 \pm 5.17$ & $95 \pm 3.66$ & $94 \pm 4.67$ & $94 \pm 2.34$ & $94 \pm 1.40$ \\
\hline SK-N-SH & Human, neuroblastoma (brain) & $100 \pm 4.14$ & $101 \pm 0.78$ & $93 \pm 4.01$ & $102 \pm 1.35$ & $98 \pm 1.70$ & $98 \pm 4.53$ \\
\hline U-373 MG & Human, glioblastoma (brain) & $100 \pm 8.15$ & $96 \pm 8.06$ & $97 \pm 4.48$ & $96 \pm 8.70$ & $95 \pm 5.41$ & $94 \pm 6.69$ \\
\hline $\mathrm{U}-87 \mathrm{MG}$ & Human, glioblastoma (brain) & $100 \pm 3.03$ & $97 \pm 5.65$ & $95 \pm 3.67$ & $95 \pm 4.6$ & $99 \pm 5.39$ & $97 \pm 4.74$ \\
\hline HEK-293 & Human, kidney & $100 \pm 6.96$ & $124 \pm 3.74$ & $126 \pm 3.55$ & $118 \pm 2.11$ & $117 \pm 3.96$ & $118 \pm 2.37$ \\
\hline HepG2 & Human, hepatoblastoma & $100 \pm 3.40$ & $95 \pm 4.11$ & $94 \pm 4.42$ & $92 \pm 4.47$ & $91 \pm 4.44$ & $90 \pm 2.09$ \\
\hline Нер3B & Human, hepatocarcinoma & $100 \pm 2.73$ & $101 \pm 1.43$ & $100 \pm 2.79$ & $99 \pm 3.13$ & $97 \pm 1.61$ & $92 \pm 0.86$ \\
\hline RAW264.7 & Mouse, macrophage & $100 \pm 2.15$ & $107 \pm 1.90$ & $110 \pm 2.02$ & $109 \pm 4.06$ & $108 \pm 6.42$ & $108 \pm 3.17$ \\
\hline 3T3-L1 & Mouse, fibroblast (preadipocyte) & $100 \pm 1.68$ & $101 \pm 0.47$ & $97 \pm 1.58$ & $98 \pm 2.32$ & $101 \pm 3.11$ & $92 \pm 3.91$ \\
\hline HIT-T15 & Hamster, pancreas & $100 \pm 0.60$ & $101 \pm 2.10$ & $100 \pm 3.40$ & $99 \pm 2.50$ & $98 \pm 3.10$ & $100 \pm 2.30$ \\
\hline HL-60 & Human, leukemia, lymphoblast & $100 \pm 2.56$ & $99 \pm 3.30$ & $100 \pm 2.43$ & $98 \pm 1.82$ & $99 \pm 2.73$ & $99 \pm 2.61$ \\
\hline HT-29 & Human, colon cancer cell & $100 \pm 4.28$ & $107 \pm 7.36$ & $104 \pm 6.67$ & $107 \pm 14.16$ & $105 \pm 13.91$ & $97 \pm 4.00$ \\
\hline NIH3T3 & Mouse, fibroblast & $100 \pm 7.56$ & $102 \pm 9.10$ & $101 \pm 2.39$ & $101 \pm 1.93$ & $101 \pm 3.94$ & $101 \pm 8.42$ \\
\hline B16F10 & Mouse, melanoma & $100 \pm 6.86$ & $101 \pm 8.66$ & $93 \pm 6.32$ & $102 \pm 4.23$ & $98 \pm 4.84$ & $98 \pm 6.26$ \\
\hline MCF-7 & Human, breast cancer & $100 \pm 1.66$ & $103 \pm 2.45$ & $105 \pm 1.95$ & $113 \pm 3.67$ & $114 \pm 2.12$ & $114 \pm 1.47$ \\
\hline $\mathrm{HaCaT}$ & Human, keratinocyte & $100 \pm 2.69$ & $96 \pm 2.08$ & $90 \pm 4.12$ & $91 \pm 3.59$ & $89 \pm 2.87$ & $89 \pm 2.90$ \\
\hline PC12 & Rat, adrenal medulla, pheochromocytoma & $100 \pm 2.92$ & $109 \pm 2.01$ & $105 \pm 0.42$ & $105 \pm 2.05$ & $103 \pm 1.19$ & $106 \pm 2.71$ \\
\hline AGS & Human, gastric adenocarcinoma & $100 \pm 0.74$ & $101 \pm 0.92$ & $94 \pm 0.51$ & $100 \pm 0.80$ & $95 \pm 1.76$ & $95 \pm 0.79$ \\
\hline BEAS-2B & Human, bronchial epithelial, normal cell & $100 \pm 5.09$ & $102 \pm 2.64$ & $107 \pm 4.50$ & $93 \pm 3.78$ & $96 \pm 1.54$ & $88 \pm 2.27$ \\
\hline LNCaP & Human, prostate cancer & $100 \pm 8.39$ & $106 \pm 6.33$ & $106 \pm 6.92$ & $104 \pm 10.50$ & $103 \pm 10.95$ & $105 \pm 8.63$ \\
\hline RBL-1 & Rat, basophilic leukemia & $100 \pm 2.55$ & $98 \pm 2.89$ & $94 \pm 0.75$ & $94 \pm 1.39$ & $94 \pm 1.71$ & $94 \pm 0.88$ \\
\hline NRK52 & Rat, kidney & $100 \pm 1.96$ & $122 \pm 2.27$ & $121 \pm 2.96$ & $121 \pm 0.95$ & $124 \pm 1.55$ & $123 \pm 2.34$ \\
\hline
\end{tabular}

the herbal components; it will therefore be necessary to define the safety of each component. In addition, studies should be conducted in suitable nonrodent model before extrapolating the results to human medicine.

\section{Conflict of Interests}

The authors have declared that no conflict of interests exists.

\section{Acknowledgment}

This work was supported by a grant from the Korea Institute of Oriental Medicine (no. K14030).

\section{References}

[1] S. D. Park, Prescriptionology, Young Lim Press, Seoul, Republic of Korea, 2003.

[2] M. Li, W. Wang, P. Wang, K. Yang, H. Sun, and X. Wang, “The pharmacological effects of morroniside and loganin isolated from liuweidihuang wan, on MC3T3-E1 cells," Molecules, vol. 15, no. 10, pp. 7403-7414, 2010.

[3] K.-S. Shim, C. J. Ma, D.-S. Kim, and J. Y. Ma, "Yukmijihwangtang inhibits receptor activator for nuclear factor- $\kappa \mathrm{B}$ ligandinduced osteoclast differentiation," Journal of Medicinal Food, vol. 14, no. 11, pp. 1439-1447, 2011.
[4] C.-R. Wu, L.-W. Lin, W.-H. Wang, and M.-T. Hsieh, "The ameliorating effects of LiuWei Dihuang Wang on cycloheximideinduced impairment of passive avoidance performance in rats," Journal of Ethnopharmacology, vol. 113, no. 1, pp. 79-84, 2007.

[5] M. Kang, J.-H. Kim, C. Cho et al., "Effects of Yukmijihwangtang derivatives (YMJd) on ibotenic acid-induced amnesia in the rat," Biological and Pharmaceutical Bulletin, vol. 29, no. 7, pp. 1431-1435, 2006.

[6] J.-J. Shen, C.-J. Lin, J.-L. Huang, K.-H. Hsieh, and M.-L. Kuo, "The effect of liu-wei-di-huang wan on cytokine gene expression from human peripheral blood lymphocytes," The American Journal of Chinese Medicine, vol. 31, no. 2, pp. 247257, 2003.

[7] S. Rho, M. Kang, B. Choi et al., "Effects of Yukmijihwang-tang derivatives (YMJd), a memory enhancing herbal extract, on the gene-expression profile in the rat hippocampus," Biological and Pharmaceutical Bulletin, vol. 28, no. 1, pp. 87-93, 2005.

[8] I. S. Shin, M. Y. Lee, H. K. Ha, C. S. Seo, and H.-K. Shin, "Inhibitory effect of Yukmijihwang-tang, a traditional herbal formula against testosterone-induced benign prostatic hyperplasia in rats," BMC Complementary and Alternative Medicine, vol. 12, article 48, 2012.

[9] OECD, "Principles on Good Laboratory Practice," 1997.

[10] Y.-M. Xue, R. Luo, B. Zhu, Y. Zhang, Y.-H. Pan, and C.-Z. Li, "Effects of liuwei dihuang pills on expressions of apoptosisrelated genes bcl-2 and Bax in pancreas of OLETF rats," Zhong Xi Yi Jie He Xue Bao, vol. 3, no. 6, pp. 455-458, 2005. 
[11] D. G. Kang, E. J. Sohn, M. K. Moon et al., "Yukmijihwang-tang ameliorates ischemia/reperfusion-induced renal injury in rats," Journal of Ethnopharmacology, vol. 104, no. 1-2, pp. 47-53, 2006.

[12] J. Wang, K. Yao, X. Yang et al., "Chinese patent medicine liu wei di huang wan combined with antihypertensive drugs, a new integrative medicine therapy, for the treatment of essential hypertension: a systematic review of randomized controlled trials," Evidence-Based Complementary and Alternative Medicine, vol. 2012, Article ID 714805, 7 pages, 2012.

[13] H. Ha, J. K. Lee, and H. Y. Lee, "Safety evaluation of Yukmijihwang-tang: assessment of acute and subchronic toxicity in rats," Evidence-Based Complementary and Alternative Medicine, vol. 2011, Article ID 672136, 8 pages, 2011.

[14] H. Ha, J. K. Lee, H. Y. Lee et al., "Evaluation of genotoxicity of Yukmijihwang-tang, a herbal formula," Regulatory Toxicology and Pharmacology, vol. 59, no. 3, pp. 391-396, 2011.

[15] B. Michael, B. Yano, R. S. Sellers et al., "Evaluation of organ weights for rodent and non-rodent toxicity studies: a review of regulatory guidelines and a survey of current practices," Toxicologic Pathology, vol. 35, no. 5, pp. 742-750, 2007.

[16] R. S. Sellers, D. Morton, B. Michael et al., "Society of toxicologic pathology position paper: organ weight recommendations for toxicology studies," Toxicologic pathology, vol. 35, no. 5, pp. 751755, 2007.

[17] C. R. Laboratories, "Clinical laboratory parameters for Crl:CD(SD) rats," 2006.

[18] World Health Organization, "General laboratory findings in clinical toxicology," in Basic Analytical Toxicology, WHO, Geneva, Switzerland, 2014.

[19] M. T. Cunningham, J. T. Brandt, M. Laposata, and J. D. Olson, "Laboratory diagnosis of dysfibrinogenemia," Archives of Pathology \& Laboratory Medicine, vol. 126, no. 4, pp. 499-505, 2002.

[20] Z. Y. Khoo, C. C. Teh, N. K. Rao, and J. H. Chin, "Evaluation of the toxic effect of star fruit on serum biochemical parameters in rats," Pharmacognosy Magazine, vol. 6, no. 22, pp. 120-124, 2010.

[21] J. F. Zilva, P. R. Pannal, and P. D. Mayne, Clinical Chemistry in Diagnosis and Treatment, England Clays, St Ives Plc, England, UK, 5th edition, 1991.

[22] C. Johnson-Delaney, Exotic Animal Companion Medicine Handbook for Veterinarians, Zoological Education Network, 1996.

[23] H. Ha, J. K. Lee, H. Y. Lee et al., "Evaluation of safety of the herbal formula Ojeok-san: acute and sub-chronic toxicity studies in rats," Journal of Ethnopharmacology, vol. 131, no. 2, pp. 410-416, 2010.

[24] H. Ha, J. K. Lee, H. Y. Lee et al., "Genotoxicity assessment of a herbal formula, Ojeok-san," Journal of Ethnopharmacology, vol. 135, no. 2, pp. 586-589, 2011.

[25] P. Barrow, "Reproduction and development of toxicology safety studies," in The Handbook of Experimental Animals: The Laboratory Rats, G. J. Krinke, Ed., pp. 11-27, Academic Press, London, UK, 2000.

[26] A. S. J. P. A. M. van Miert, “The use in animals of drugs licensed for human use only," in Comparative Veterinary Pharmacology, Toxicology and Therapy, A. S. J. P. A. M. van Miert, M. G. Bogaert, and M. Debackere, Eds., pp. 489-500, MTP Press, Boston, Mass, USA, 1986. 


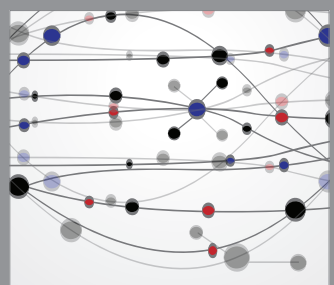

The Scientific World Journal
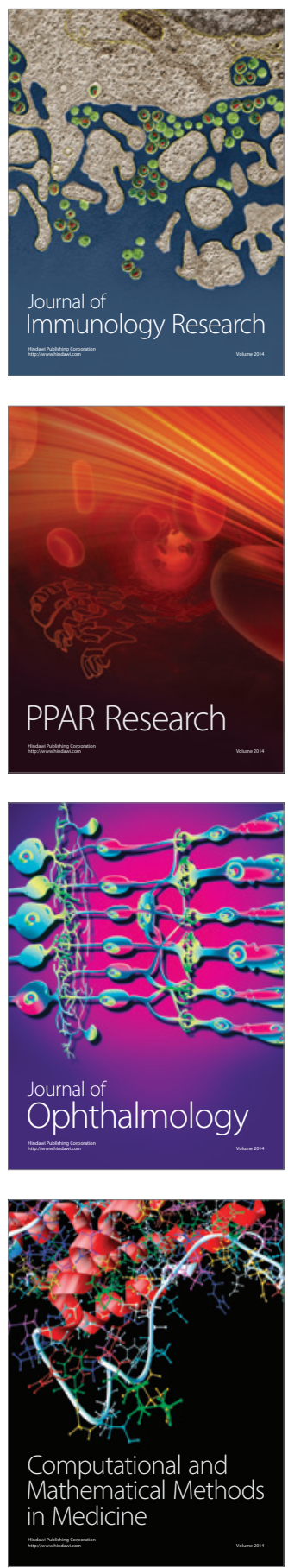

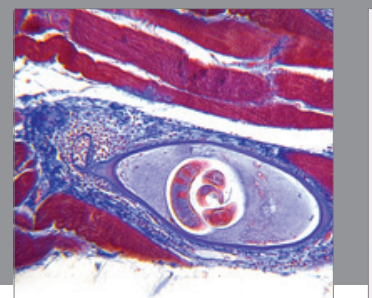

Gastroenterology

Research and Practice
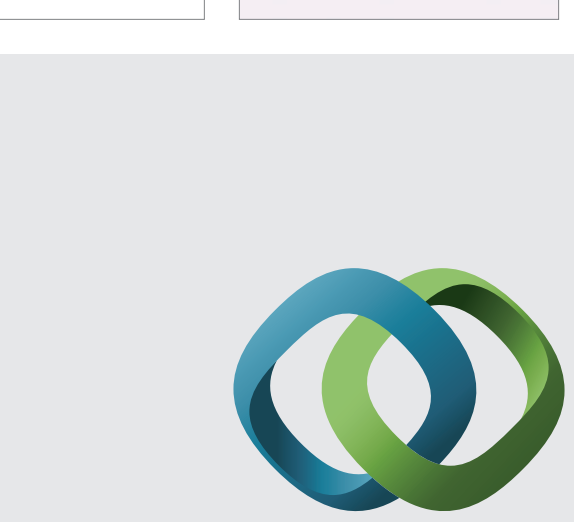

\section{Hindawi}

Submit your manuscripts at

http://www.hindawi.com
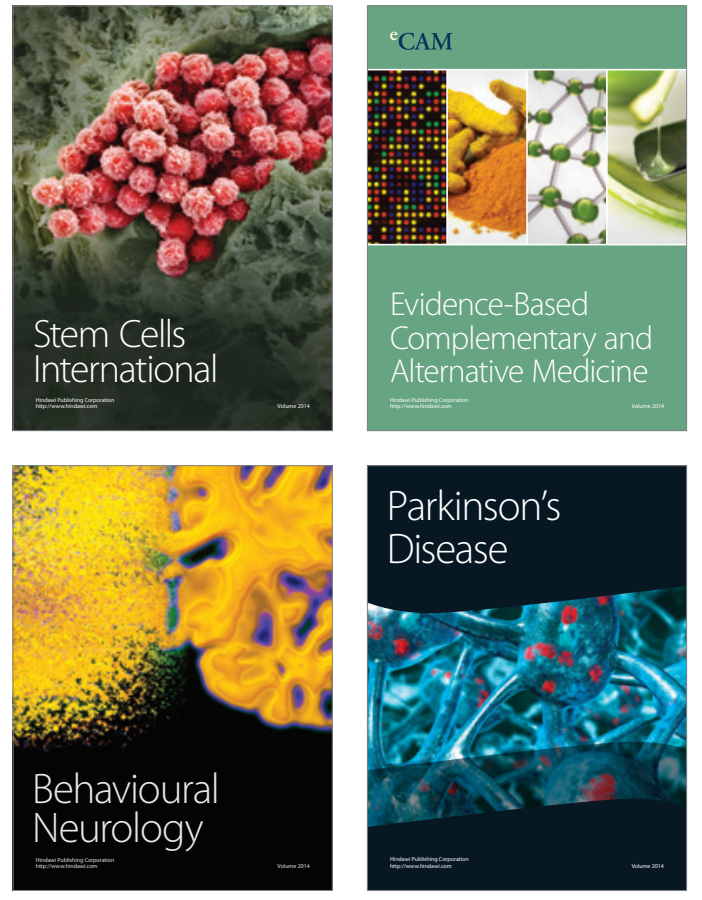
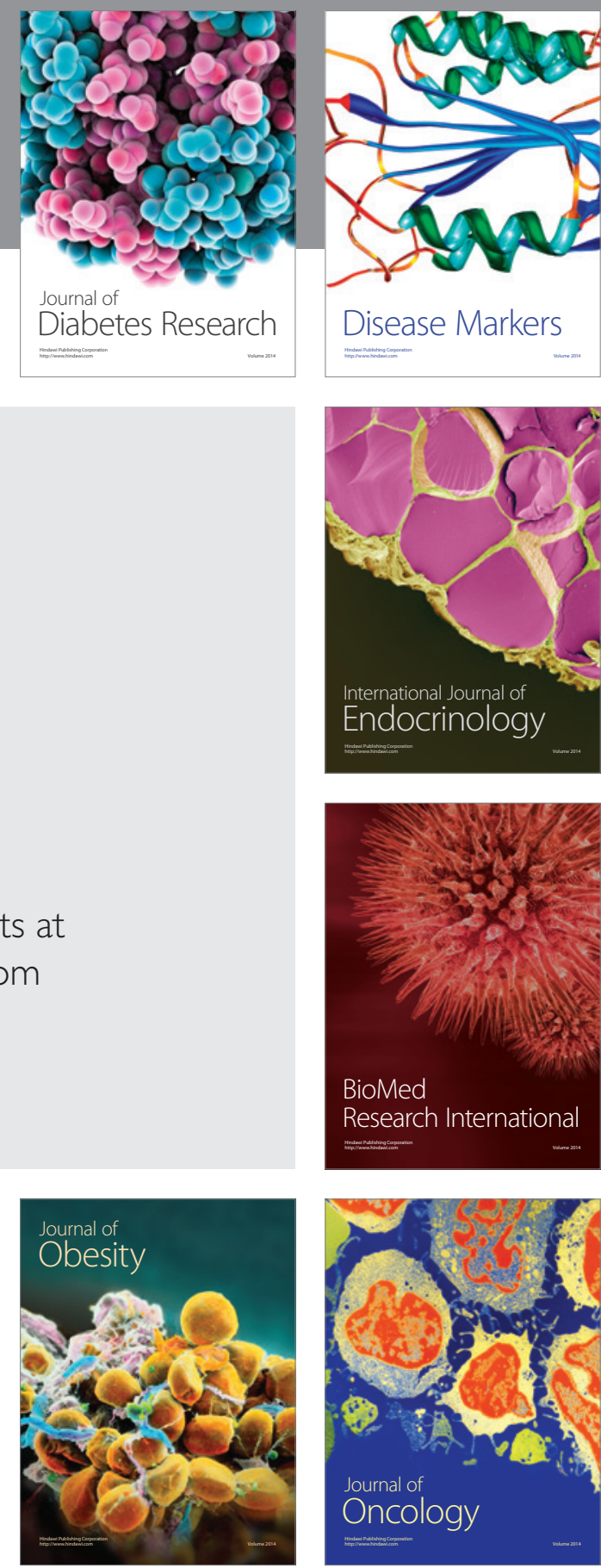

Disease Markers
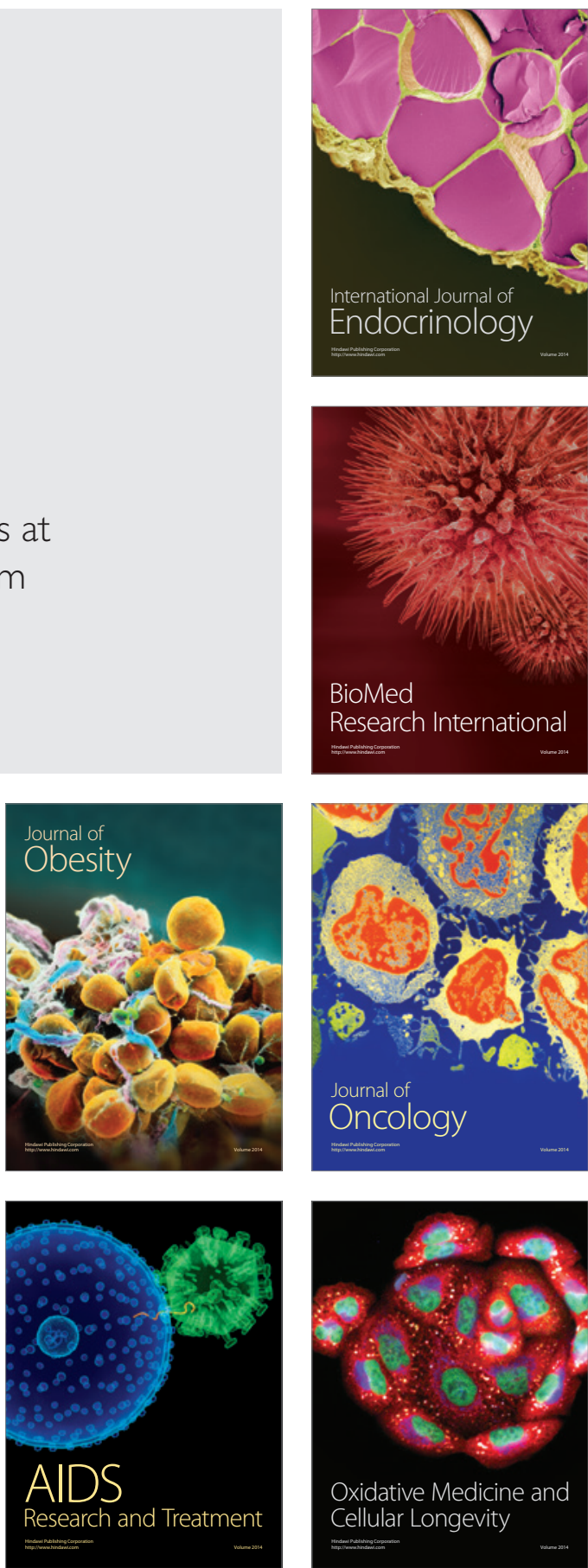